\title{
Direct Synthesis of Porous Carbon Materials Prepared from Diethyldithiocarbamate Metal Complexes and Their Electrochemical Behavior
}

\author{
Herculano V. da Silva, ${ }^{a}$ Arilza O. Porto, ${ }^{a}$ Cristiano C. Caliman, ${ }^{b}$ Rubens L. de Freitas Filho, ${ }^{a}$ \\ Alexandre A. C. Cotta, ${ }^{c}$ Waldemar A. A. Macedo ${ }^{d}$ and Ana Paula C. Teixeira*,a \\ ${ }^{a}$ Departamento de Química, Universidade Federal de Minas Gerais (UFMG), \\ 31270-901 Belo Horizonte-MG, Brazil \\ ${ }^{b}$ Departamento de Química, Universidade Federal do Espírito Santo (UFES), \\ 29075-910 Vitória-ES, Brazil
}

\author{
'Departamento de Física, Universidade Federal de Lavras (UFLA), 37200-000 Lavras-MG, Brazil \\ ${ }^{d}$ Centro de Desenvolvimento de Tecnologia Nuclear (CDTN), 31270-901 Belo Horizonte-MG, Brazil
}

\begin{abstract}
Porous carbon materials were prepared at low temperatures via thermal decomposition of iron, nickel and cobalt $N, N$-diethyldithiocarbamates (DDT). X-ray diffraction data showed two peaks at $2 \theta\left(25.5^{\circ}\right.$ and $\left.43.5^{\circ}\right)$ that indicate the presence of graphite-like structures. Raman spectra displayed D and G bands in the range from 1312 to $1321 \mathrm{~cm}^{-1}$ and 1587 to $1593 \mathrm{~cm}^{-1}$, respectively, which were fitted with 4 components. All spectra showed two low intensity D* $\left(1190 \mathrm{~cm}^{-1}\right)$ and D" $\left(1500 \mathrm{~cm}^{-1}\right)$ bands, assigned to $\mathrm{sp}^{2}-\mathrm{sp}^{3}$ bonds in disordered carbonaceous materials and amorphous carbon, respectively. Transmission electron microscopy images showed agglomerates of spherical particles formed by graphitic segments. The results showed that the carbon material obtained from iron $N, N$-diethyldithiocarbamate, $\mathrm{Fe}(\mathrm{DDT})_{3}$, is structurally better organized than the others and the pore size distribution curves confirmed that this material presents high degree of mesoporosity. Voltammetric curves obtained using $\mathrm{KOH}$ and $\mathrm{H}_{2} \mathrm{SO}_{4}$ electrolytes showed hysteresis behavior typical of capacitors charge/discharge process. The carbon material prepared from $\mathrm{Fe}(\mathrm{DDT})_{3}$ displayed the highest specific capacitance in acidic media, $59 \mathrm{~F} \mathrm{~g}^{-1}$, which was associated to its high degree of mesoporosity.
\end{abstract}

Keywords: carbon materials, diethyldithiocarbamate complexes, electrochemical application

\section{Introduction}

Different physical methods have been used to prepare carbon nanomaterials such as laser ablation, ${ }^{1,2}$ arch discharge ${ }^{3,4}$ and combustion. ${ }^{5,6}$ Thermal decomposition of organic and organometallic precursors ${ }^{7-9}$ has been presented as a viable alternative to physical methods which use harsh synthesis conditions and yield small amount of products. Different carbon-rich precursors are used to obtain these carbon nanostructures, which can be transformed into graphitic carbon materials of different sizes and shapes. Among these organic precursors, alkynes olygoine derivatives are good candidates due to their high chemical instability, which allows them to undergo different chemical reactions. ${ }^{10}$ Various carbon precursors

*e-mail: anapaula.cta1@gmail.com such as benzene, ${ }^{11}$ sucrose ${ }^{12}$ and phenol resin, ${ }^{13}$ are also suitable for the synthesis of carbon materials. Similarly, the pyrolysis of organometallic precursors, such as cobalt acetylacetonate, ${ }^{14}$ also yields carbon nanostructures presenting good electrochemical performance which depends on surface area as well as the porosity of these structures. The major problem associated with the method described above is the presence of encapsulated metals.

Porous carbon materials are excellent candidates for electrodes in supercapacitors. ${ }^{15,16}$ For these materials pore accessibility plays a significant role in the charge storage and the specific capacitance reaches a maximum value when the pore size matches the maximum electrolyte ion dimension. ${ }^{17}$ For carbon nanomaterials the surface areas range from 300 to $600 \mathrm{~m}^{2} \mathrm{~g}^{-1}$ and are responsible for electrolyte wetting and rapid ionic motions necessary for 
a satisfactory electrochemical performance. ${ }^{18}$ Different methods have been used to increase the specific capacitance of these materials, such as the chemical or physical activation, which leads to an increase of their surface area, and also the decoration of their accessible external surface with redox active materials such as metal oxides and hydroxides. ${ }^{19}$ It has been shown that three dimensional (3D) porous graphitic carbon provides good conductivity and porous structure which is formed by interconnected porous networks. These networks decrease the ion transport resistance and diffusion distances and also display large accessible surface areas. ${ }^{20}$

In this work, carbon materials (CM) were prepared using thermal decomposition of iron, nickel and cobalt $N, N$-diethyldithiocarbamates (DDT) ethanolic solutions in nitrogen atmosphere. The solvent, ethanol, and the metal complexes were used as carbon source and the latter also worked as catalysts for the graphitization process. The advantage of the simplified synthetic route proposed is the use of low working temperatures and production of carbon structures with high degree of mesoporosity. The obtained materials were characterized by Raman spectroscopy, X-ray diffraction (XRD), $\mathrm{N}_{2}$ adsorption measurements, X-ray photoelectron spectroscopy (XPS), thermogravimetric (TG) and derivative thermogravimetric (DTG) analyses, and transmission electron microscopy (TEM). The electrochemical behavior was studied by cyclic voltammetry $(\mathrm{CV})$ in $\mathrm{KOH}$ and $\mathrm{H}_{2} \mathrm{SO}_{4}$ aqueous solutions.

\section{Experimental}

\section{Synthesis of metal complexes}

For the syntheses of iron(III) $N, N$-diethyldithiocarbamate $\left(\mathrm{Fe}(\mathrm{DDT})_{3}\right)$, nickel(II) $N, N$-diethyldithiocarbamate $\left(\mathrm{Ni}(\mathrm{DDT})_{2}\right)$ and cobalt(II) $N, N$-diethyldithiocarbamate $\left(\mathrm{Co}(\mathrm{DDT})_{2}\right)$, the following metal salts were used: $\mathrm{Fe}\left(\mathrm{NO}_{3}\right)_{3} \cdot \mathrm{H}_{2} \mathrm{O}(0.205 \mathrm{~g}), \mathrm{Ni}\left(\mathrm{C}_{2} \mathrm{H}_{3} \mathrm{O}_{2}\right)_{2} \cdot 4 \mathrm{H}_{2} \mathrm{O}(0.208 \mathrm{~g})$, $\mathrm{Co}\left(\mathrm{C}_{2} \mathrm{H}_{3} \mathrm{O}_{2}\right)_{2} .4 \mathrm{H}_{2} \mathrm{O}(0.140 \mathrm{~g})$ and sodium $N, N$-diethyldithiocarbamate (NaDDT, Sigma-Aldrich, $0.100 \mathrm{~g})$. The metal salts and NaDDT were both diluted in ethanol $(16 \mathrm{~mL})$ and distilled water $(4 \mathrm{~mL})$. The solutions were kept under stirring for $60 \mathrm{~min}$ at room temperature. The obtained solids were filtered and washed with ethanol $(200 \mathrm{~mL})$, acetone $(200 \mathrm{~mL})$ and distilled water $(500 \mathrm{~mL})$. Finally, the solids were dried for $2 \mathrm{~h}$ at $60^{\circ} \mathrm{C}$.

TG/DTG analyses of the prepared metal complexes were carried out in Shimadzu model TG $60 \mathrm{H}$ equipment with $10{ }^{\circ} \mathrm{C} \mathrm{min}-1$ heating rate under $50 \mathrm{~mL} \mathrm{~min}^{-1}$ air flux in order to determine their decomposition temperatures.

\section{Synthesis and characterization of carbon materials}

Ethanolic solutions $(25 \mathrm{~mL})$ of each metal complex (25 mg) were prepared and placed in a plastic syringe (22 $\mathrm{mL}$ and $19 \mathrm{~mm}$ diameter) coupled to a quartz tube. This tube was put in a tubular furnace in which the solutions were slowly introduced. The thermal decomposition experiments were carried out at $700{ }^{\circ} \mathrm{C}$ under nitrogen flow $\left(10 \mathrm{~mL} \mathrm{~min}{ }^{-1}\right)$ for $180 \mathrm{~min}$. The final materials were collected from the tube walls and three samples were obtained, $\mathrm{CMFe}, \mathrm{CMNi}$ and $\mathrm{CMCo}$ derived from $\mathrm{Fe}(\mathrm{DDT})_{3}, \mathrm{Ni}(\mathrm{DDT})_{2}$ and $\mathrm{Co}(\mathrm{DDT})_{2}$, respectively.

XRD patterns were acquired using Shimadzu XRD 7000 diffractometer with $\mathrm{CuK} \alpha$ radiation, scanning rate $0.01^{\circ} \mathrm{min}^{-1}$. TG/DTG measurements were performed under the same conditions as above. Raman spectroscopy measurements were carried out in Senterra Bruker equipment with CCD (charge-coupled device) detector. The samples were excited with $633 \mathrm{~nm}$ laser ( $2 \mathrm{~mW}$ power output). Raman spectra are the average of five spectra obtained with 10 scans each and 10 s counting time per point. Peak analysis was carried out after subtraction of background by using a linear baseline function, and peak fitting was then performed using Voigt functions to find the peak contribution of amorphous and graphitic carbon to the broad $\mathrm{G}$ band. ${ }^{21-23}$ In order to avoid the influence of amorphous carbon with different particle sizes on $\mathrm{D}$ band broadening, the $I_{D} / I_{G}$ ratio was calculated using the intensity (I) instead of area of Raman peaks as discussed in the literature. ${ }^{24}$ XPS measurements were carried out in ultrahigh vacuum chamber (base pressure lower than $2.0 \times 10^{9}$ mbar) using a monochromatic Al K $\alpha$ X-ray source with output power set at $350 \mathrm{~W}$ and a SPECS hemispherical electron energy analyzer PHOIBOS 150 MCD. Survey and high-resolution spectra were recorded with band pass energies of 50 and $40 \mathrm{eV}$, respectively. The scans were acquired using a flood gun emission current of $0.8 \mu \mathrm{A}$ for a charge compensation. For these measurements, a thick layer $(0.5 \mathrm{~mm})$ of the samples was impregnated on a carbon tape in order to ensure that $\mathrm{C} 1 \mathrm{~s}$ signal from this tape did not interfere with sample spectrum. CasaXPS program ${ }^{25}$ was used to analyze all XPS data. Scanning electron microscope (SEM) images were acquired using FIB-Quanta 200 microscope with $30 \mathrm{kV}$ secondary and backscattered electron detectors. The samples were dispersed in acetone and deposited on a silicon wafer by evaporation. TEM images were acquired in a TEM-FEI G220-FEI2006 model at $200 \mathrm{kV}$. For these analyses the samples were dispersed in acetone in ultrasonic bath and dripped in a holey carbon film on 200 mesh copper grid. Nitrogen sorption analysis was carried out using an AutosorbQ equipment (Quantachrome) at $-196{ }^{\circ} \mathrm{C}$ in the 
relative pressure $\left(\mathrm{P} / \mathrm{P}_{0}\right)$ range of $3.38 \times 10^{-2}$ to 1.0 . Prior to the analysis the samples were outgassed at $200{ }^{\circ} \mathrm{C}$ for $12 \mathrm{~h}$ under vacuum conditions.

Cyclic voltammetry measurements were performed using Autolab PGSTAT128N equipment. $1.0 \mathrm{mg}$ of each sample was dispersed in $200 \mu \mathrm{L}$ ethanol and $10 \mu \mathrm{L} \mathrm{Nafion}^{\circledR}$ in ultrasonic bath for $5 \mathrm{~min}$. Next, $10 \mu \mathrm{L}$ of the generated dispersion was deposited onto a carbon glassy electrode with $0.166 \mathrm{~cm}^{2}$ area. Cyclic voltammograms were acquired using a voltage window from 0.5 to $-0.5 \mathrm{~V}$ for basic media and from 0.0 to $1.0 \mathrm{~V}$ for acidic media at scan rates of 10 , 50,100 and $200 \mathrm{mV} \mathrm{s}^{-1}$. The measurements were carried out using $\mathrm{Hg} / \mathrm{HgO}$ reference electrode and graphite as counter electrode in a $\mathrm{KOH}$ aqueous solution $(0.1 \mathrm{M})$. The voltammograms were also acquired in $\mathrm{H}_{2} \mathrm{SO}_{4}$ aqueous $(1.0 \mathrm{M})$ using $\mathrm{Ag} / \mathrm{AgCl}$ reference electrode. In order to saturate the solution with oxygen, this gas was introduced in these solutions during $5 \mathrm{~min}$. The values of specific capacitance were calculated with Metrohm Autolab B.V. software (version 1.10).

\section{Results and Discussion}

TG/DTG analyses of the metal complexes were performed in order to investigate their thermal stabilities for later experiments in the tube furnace. For $\mathrm{Fe}(\mathrm{DDT})_{3}$ decomposition started at $209{ }^{\circ} \mathrm{C}$ and ended at $280{ }^{\circ} \mathrm{C}$, with a DTG peak at $260{ }^{\circ} \mathrm{C}$ (Figure 1a). For Ni(DDT) $)_{2}$ decomposition was observed in the range from 266 to $376{ }^{\circ} \mathrm{C}$ and the maximum of DTG was at $349{ }^{\circ} \mathrm{C}$, as described in the literature ${ }^{26}$ for this metal complex (Figure 1b). For Co(DDT) $)_{2}$ the decomposition temperature was observed at approximately $348{ }^{\circ} \mathrm{C}$ (Figure 1c), the temperature at which $\mathrm{CoS}$ is formed. ${ }^{27}$ The maximum values of DTG obtained for the three materials showed that $\mathrm{Fe}(\mathrm{DDT})_{3}$ is less thermally stable than the other two metal complexes. It implies that carbon materials prepared from this metal complex are expected to be formed at lower temperatures than the ones prepared from $\mathrm{Ni}(\mathrm{DDT})_{2}$ and $\mathrm{Co}(\mathrm{DDT})_{2}$.

The synthesized CM were characterized by XRD. As displayed in Figures 2a-2c, the diffraction peaks observed at approximately $2 \theta 25.5^{\circ}$ and $43.5^{\circ}$ indicate the presence of graphite-like structures. ${ }^{28}$ The multiphase nature of those samples explains the broad (002) line profiles. These asymmetric (002) peaks are consistent with carbon structures presenting different interplanar distances, $<\mathrm{d}_{002}>$, associated to the in-plane graphite-like lattice parameter, $<\mathrm{a}>{ }^{29}$ This peak asymmetry is also associated to the presence of another peak in its left-hand side, assigned as $\gamma$ in Figures 2a-2c, related to the packing distance of saturated
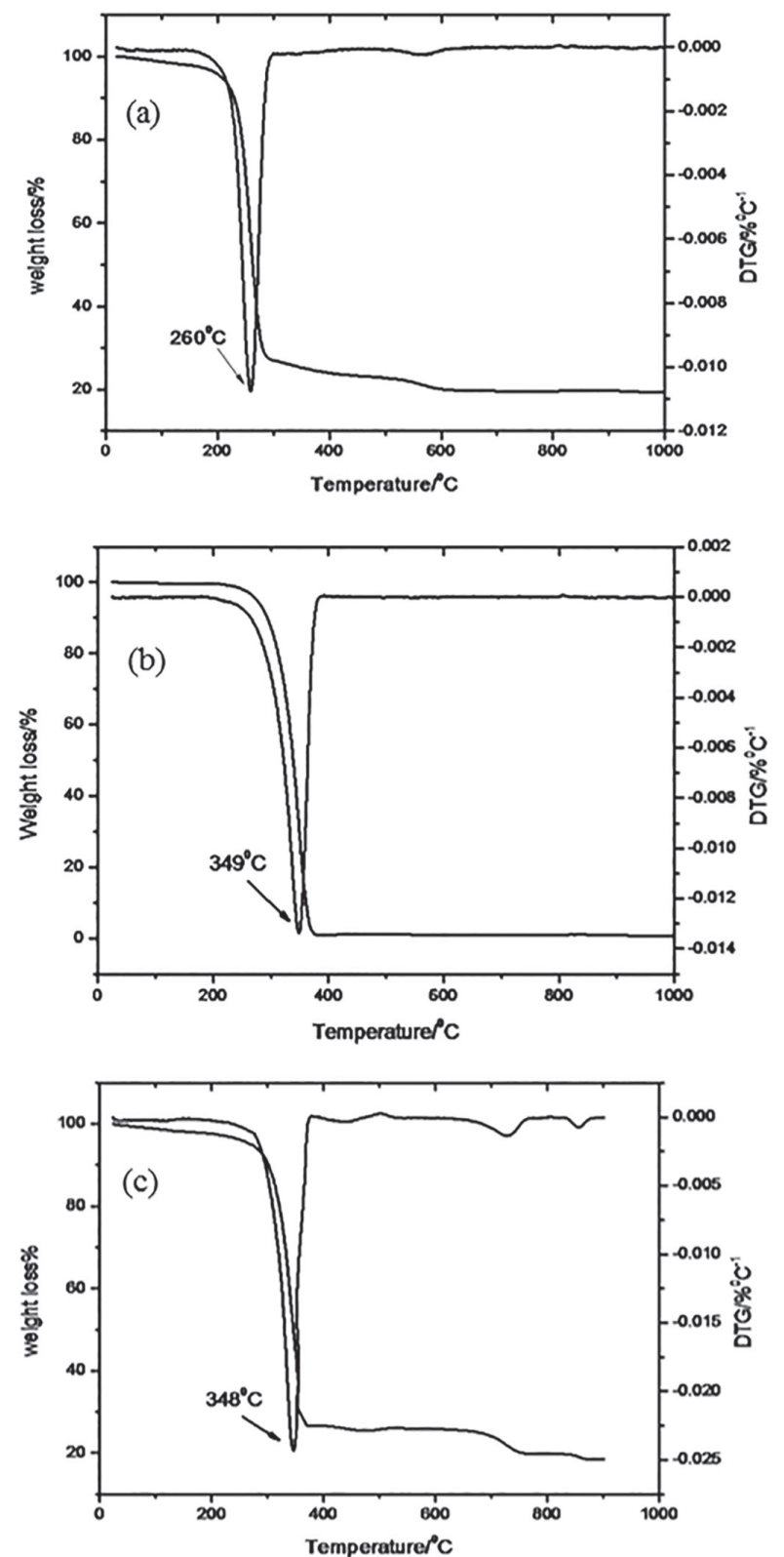

Figure 1. TG/DTG curves of (a) $\mathrm{Fe}(\mathrm{DDT})_{3}$; (b) $\mathrm{Ni}(\mathrm{DDT})_{2}$ and (c) $\mathrm{Co}(\mathrm{DDT})_{2}$.

carbon structures as discussed elsewhere for other carbon materials. ${ }^{30}$ These (002) line profiles were fitted with 2 Gaussian peaks ${ }^{28}$ for CMFe, with $2 \theta=24.20^{\circ}$ (full width at half maximum (FWHM): 7.0 ) and $25.80^{\circ}$ (FWHM: 8.3), see Figure 2a. For CMNi, 3 Gaussian peaks were fitted: $2 \theta=23.00^{\circ}$ (FWHM: 8.0), $25.60^{\circ}$ (FWHM: 3.0) and $29.90^{\circ}$ (FWHM: 8.9) (Figure 2b). For CMCo (Figure 2c), 3 Gaussian peaks were found at $2 \theta=23.20^{\circ}$ (FWHM: 8.3), $25.70^{\circ}$ (FWHM: 3.0) and $30.80^{\circ}$ (FWHM: 7.3). Interplanar distances $\left\langle\mathrm{d}_{002}>=3.449,3.469\right.$ and $3.462 \AA$ were calculated for $\mathrm{CMFe}, \mathrm{CMNi}$ and $\mathrm{CMCo}$, respectively, using $2 \theta$ position of the main component, assigned as $\mathrm{g}$. These $<\mathrm{d}_{002}>$ values are bigger than the one expected for 

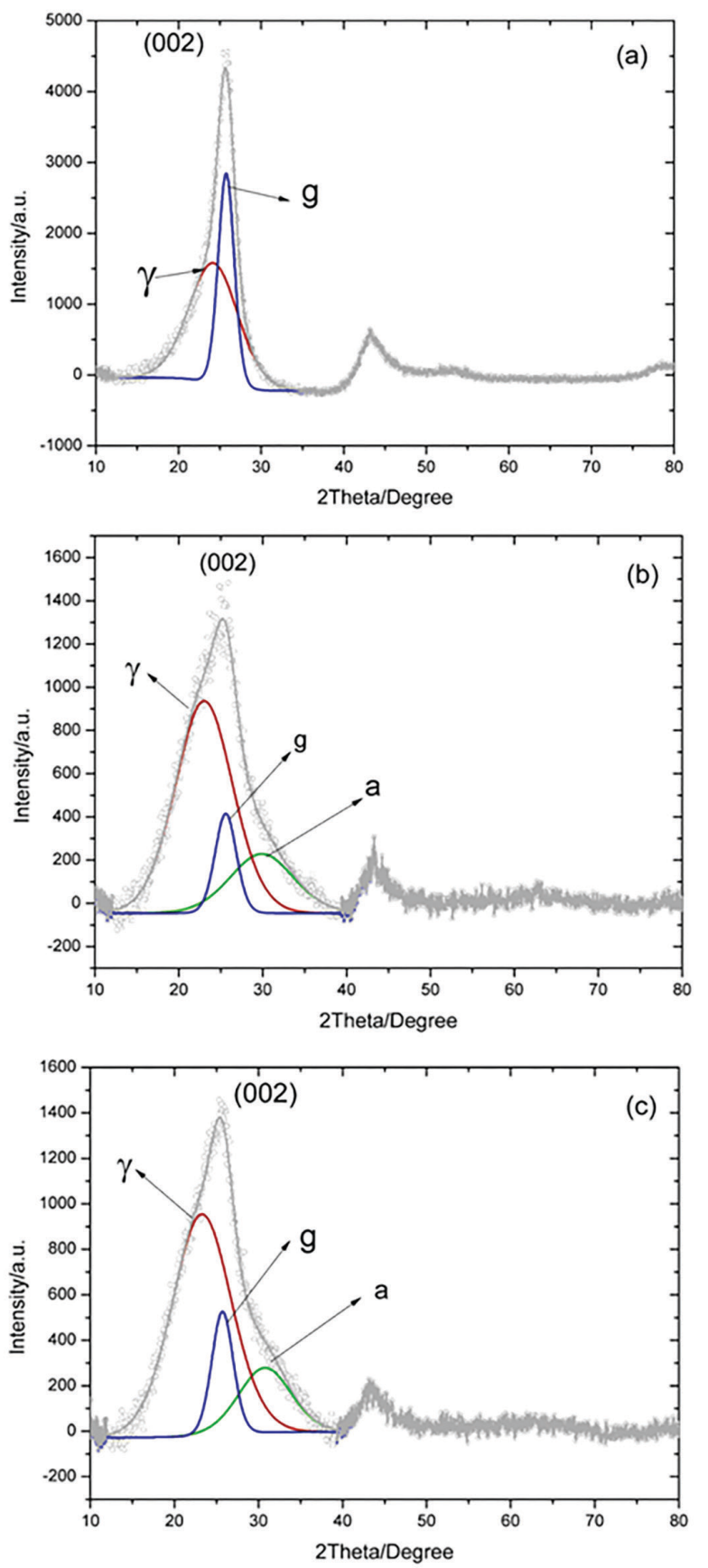

Figure 2. XRD patterns of (a) CMFe; (b) CMNi and (c) CMCo. $\gamma$ : saturated carbon structures; g: graphite main component; a: graphite with distorted interplanes.

interlayer spacing of graphite, $<\mathrm{d}_{002}>=3.36 \AA{ }^{30}$ and are consistent with carbon structures presenting low degree of graphitization. The components assigned as "a" at the right-hand side of (002) peaks at $2 \theta=29.90^{\circ}$ and $30.80^{\circ}$ for $\mathrm{CMNi}$ and $\mathrm{CMCo}$, respectively, correspond to interplane distortions caused by high lattice strain, as described in theoretical studies in the literature. ${ }^{31} \mathrm{XRD}$ results show that $\mathrm{CMNi}$ and CMCo samples present a more pronounced $\gamma$ peak indicating that for these samples more disorganized carbon phases are present. Metal carbide or sulfide peaks were not observed.

As discussed by Feret ${ }^{32}$ for calcinated and graphitic cokes prepared at low temperatures, the degree of graphitization (DOG) can be estimated with more accuracy using a ratio of the normalized peak areas which are the contributions for (002) diffraction line. In these samples, the peak contribution in the left part of the peak shoulder, at smaller angles, is assigned to an ordinary calcined coke. The other peak contribution which is shifted to higher angles corresponds to the graphitic part of the coke material. For the obtained CM samples, the evaluation of DOG values of CM materials was difficult to perform due to the presence of more than two peaks in the (002) peak profile as discussed above, making this estimation inappropriate due to the overlapping of more than two peak areas in the g peak.

Raman spectra of the samples as well as the fitting results are shown in Figure 3. D and $\mathrm{G}$ bands were observed in the range of 1312 to $1321 \mathrm{~cm}^{-1}$ and 1587 to $1593 \mathrm{~cm}^{-1}$, respectively, and in all spectra 4 components were fitted..$^{33}$ These are the two main bands observed in the Raman spectra of carbonaceous materials..$^{34} \mathrm{D}$ band is associated to the vibrations of carbon atoms with dangling $\mathrm{sp}^{3}$ bonds for the in-plane terminations of disordered graphite..$^{35}$ $\mathrm{G}$ band is related to the vibrations in all $\mathrm{sp}^{2}$ bonded carbon atoms in a two-dimensional hexagonal lattice, and it is assigned to a $\mathrm{C}-\mathrm{C} \mathrm{E}_{2 \mathrm{~g}}$ stretching mode. ${ }^{36,37} \mathrm{~A}$ weak peak was observed at approximately $2700 \mathrm{~cm}^{-1}$ corresponding to the $2 \mathrm{D}$ band. ${ }^{35,38,39}$

All spectra showed two low intensity bands at 1190 (D*) and $1500 \mathrm{~cm}^{-1}$ (D"). These bands have been reported in recent studies on spectra of carbon black, ${ }^{40}$ graphene oxide ${ }^{41}$ as well as disordered and amorphous carbon. ${ }^{24}$ Some authors suggest that the presence of a $\mathrm{D}^{*}$ band may be associated with the formation of $\mathrm{sp}^{2}-\mathrm{sp}^{3}$ bonds in disordered carbonaceous materials, ${ }^{40,41}$ while D" band may be related to the presence of amorphous carbon in the prepared samples. ${ }^{40,42,43}$ Raman spectrum of CMFe (Figure 3a) displayed the following bands: D* $\left(1175 \mathrm{~cm}^{-1}\right), \mathrm{D}\left(1318 \mathrm{~cm}^{-1}\right), \mathrm{D}^{\prime \prime}\left(1473 \mathrm{~cm}^{-1}\right)$ and a broad $\mathrm{G}$ band $\left(1587 \mathrm{~cm}^{-1}\right)$. The position of the $\mathrm{G}$ band at $1587 \mathrm{~cm}^{-1}$ is shifted compared to the one observed for ideal graphite, $1575 \mathrm{~cm}^{-1} .{ }^{39}$ In fact, for highly disorganized graphite materials the appearance of a band at $1620 \mathrm{~cm}^{-1}$, with $\mathrm{E}_{2 \mathrm{~g}}$ symmetry, called D' band, was observed ${ }^{44}$ According to Ferrari and Robertson, ${ }^{24}$ this D' band can merge with the $\mathrm{G}$ band leading to its broadening, which is characteristic of highly disordered materials with small grain sizes. Then, the main signal observed near $1587 \mathrm{~cm}^{-1}$ in Raman spectra may also have the contribution of this D' band as described in the 

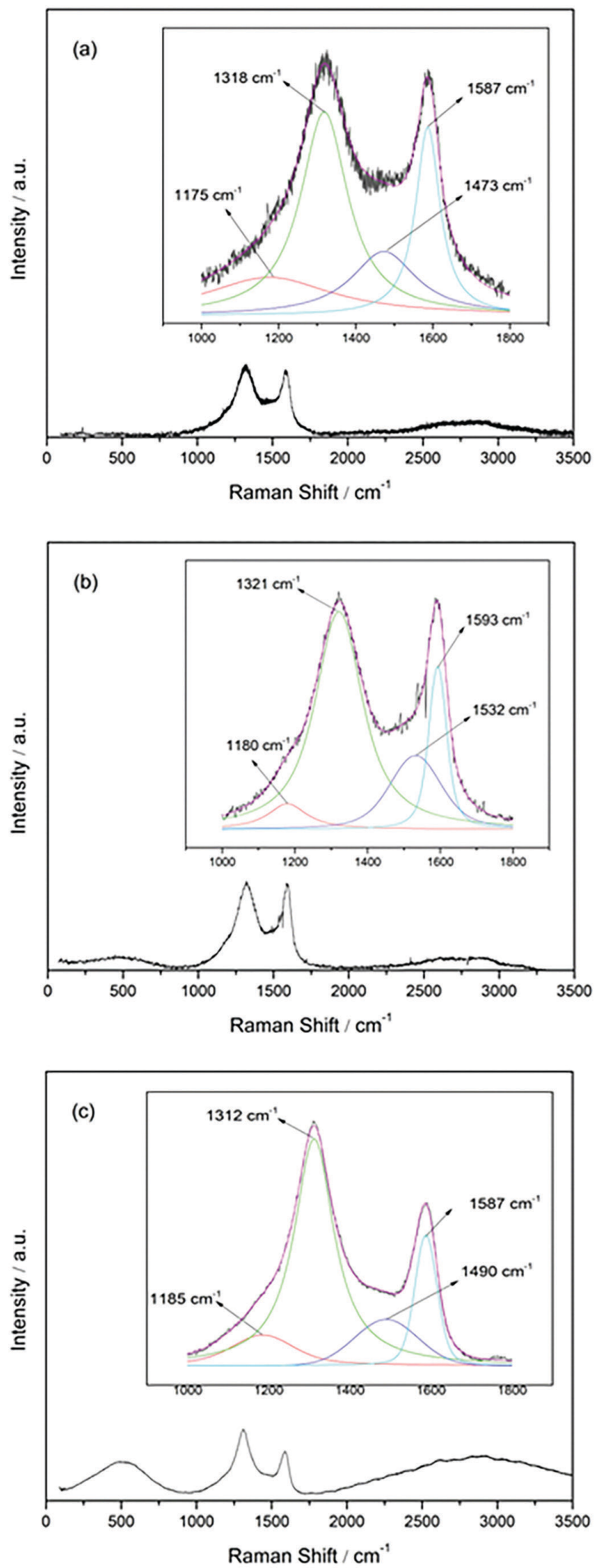

Figure 3. Raman spectra of (a) CMFe; (b) CMNi and (c) CMCo.

literature. ${ }^{40,43}$ Some authors also associate the appearance of this band with functionalization in the carbonaceous materials ${ }^{44}$ and disordered graphitic materials. ${ }^{36}$
For CMNi (Figure 3b), the $\mathrm{G}$ band $\left(1593 \mathrm{~cm}^{-1}\right)$ is at higher wavenumber compared to the one of CMFe, indicating the presence of more distorted $\mathrm{sp}^{2}$-hybridized carbon rings. For $\mathrm{CMCo}$, the $\mathrm{G}$ band is downshifted to $1587 \mathrm{~cm}^{-1}$, the same value observed for CMFe. However, the $\mathrm{I}_{\mathrm{D}}, / \mathrm{I}_{\mathrm{G}}$ peak ratio, which is associated to amorphous carbon, calculated for the $\mathrm{CMFe}\left(\mathrm{I}_{\mathrm{D}}, / \mathrm{I}_{\mathrm{G}}=0.25\right)$, is lower than the ratio obtained for $\mathrm{CMNi}\left(\mathrm{I}_{\mathrm{D}}, / \mathrm{I}_{\mathrm{G}}=0.66\right)$ and $\mathrm{CMCo}$ $\left(\mathrm{I}_{\mathrm{D}^{\prime}} / \mathrm{I}_{\mathrm{G}}=0.32\right)$, which indicates that $\mathrm{CMFe}$ has a more wellorganized structure. ${ }^{41}$ The high value of $\mathrm{I}_{\mathrm{D}} / \mathrm{I}_{\mathrm{G}}$ peak ratio is commonly related to a larger number of structural defects and imperfections in carbon materials. $\mathrm{I}_{\mathrm{D}} / \mathrm{I}_{\mathrm{G}}$ peak ratios calculated for CMFe, CMNi and CMCo were 1.09, 1.14 and 1.77 , respectively. These values indicate a low degree of graphitization and are very similar to those ratios obtained for carbon nanotubes and nanofibers fabricated on tubular porous $\mathrm{Al}_{2} \mathrm{O}_{3}$ by chemical vapor deposition. ${ }^{45}$ The highest value of $\mathrm{I}_{\mathrm{D}} / \mathrm{I}_{\mathrm{G}}$ peak ratio obtained for CMCo indicates the presence of highly disorganized structures. Raman results are in agreement with XRD data which showed that for CMNi (Figure 2b) and CMCo (Figure 2c), the $\gamma$ peaks associated to a more disorganized carbon phases are more intense than the one observed for CMFe (Figure 2a).

Raman spectra of CMNi (Figure 3b) and CMCo (Figure 3c) presented a broad band around $500 \mathrm{~cm}^{-1}$, which is assigned to amorphous carbon. ${ }^{46}$

Tuinstra and Koenig ${ }^{39}$ established an equation to determine in-plane crystallite sizes (La) by using Raman data. Knight and White ${ }^{47}$ derived an empirical expression to determine La values of different graphite systems using $\lambda=514 \mathrm{~nm}$ laser line and it was shown that the $\mathrm{I}_{\mathrm{D}} / \mathrm{I}_{\mathrm{G}}$ ratio was strongly dependent on the laser energy. Recently, Cançado et al.$^{48}$ obtained a general expression for La from a systematic study of nanographite samples (equation 1) for laser energies in the visible range. La values were calculated for $\mathrm{CMFe}, \mathrm{CMNi}$ and $\mathrm{CMCo}$ using this equation applied for experiments carried out with lasers of any energy:

$\mathrm{La}(\mathrm{nm})=\left(2.4 \times 10^{-10}\right) \lambda_{1}^{4}\left(\frac{\mathrm{I}_{\mathrm{D}}}{\mathrm{I}_{\mathrm{G}}}\right)^{-1}$

where $\lambda_{1}$ is the wavelength of laser radiation in nanometers. La values calculated (equation 1) were 33.35, 33.79 and $21.77 \mathrm{~nm}$ for $\mathrm{CMFe}, \mathrm{CMNi}$ and $\mathrm{CMCo}$, respectively.

It is well known that catalytic graphitization process of carbonaceous materials can occur in the presence of different metals, and some transition metals such as $\mathrm{Fe}$, Co and $\mathrm{Ni}$ are used to lower the temperature of graphitization. ${ }^{49}$ Romero et al. ${ }^{50}$ also showed that carbon nanotubes produced using $\mathrm{Fe}$ as catalyst present higher degree of graphitization than the ones produced with Co. For carbon materials 
in general, highly graphitized structures present high oxidation temperatures, however, XRD data showed that the low temperatures used in this work to obtain CM materials were unable to form highly graphitized structures. Thermal stability of CM structures were investigated by TG/DTG analyses (Figure 4). As can be observed in the DTG curves, the temperature range of thermal decomposition is wider for $\mathrm{CMCo}$ and $\mathrm{CMNi}$ compared to $\mathrm{CMFe}$, which implies that the latter presents higher degree of structural order compared to the others. This fact is strongly supported by XRD and Raman results previously discussed. Some authors have emphasized the broadening of DTG peak of multicomponent carbon nanotubes ${ }^{51}$ and graphitic carbon ${ }^{52}$ due to the presence of different defects such as multishell graphitic particles and amorphous carbon. It is important to observe the asymmetry of the DTG peaks of CMNi (Figure 4b) and CMCo (Figure 4c), which is probably related to the oxidation events of amorphous carbon phases. XRD results also showed that these two samples present higher amount of disorganized carbon phases which is assigned to $\gamma$ component of (002) diffraction profile. In TG curves of carbon materials, the weight losses observed at low temperatures, usually between 200 and $400{ }^{\circ} \mathrm{C}$, are associated to amorphous carbon. ${ }^{53}$ Finally, it is important to emphasize that the lower oxidation temperature observed for the precursor $\mathrm{Fe}(\mathrm{DDT})_{3}$ compared to $\mathrm{Ni}(\mathrm{DDT})_{2}$ and $\mathrm{Co}(\mathrm{DDT})_{2}$, as previously discussed, should be responsible for the production of a more organized carbon material in this case. For the precursor $\mathrm{Fe}(\mathrm{DDT})_{3}$, the formation of the carbon structures starts at lower temperature, therefore, during the process of thermal decomposition of this metal complex there is a greater probability of formation of more organized structures compared to the other precursors.

The oxidation temperatures were determined as the inflection points in DTG curves. It was observed that CMFe showed the lowest value, $448{ }^{\circ} \mathrm{C}$, compared to $\mathrm{CMNi}$, $500{ }^{\circ} \mathrm{C}$, and $\mathrm{CMCo}, 580{ }^{\circ} \mathrm{C}$ (Figure 4). Despite the fact that $\mathrm{CMFe}$ presents a more ordered structure compared to the others, as discussed for XRD and Raman results, it displayed the lowest oxidation temperature. It seems that for these materials the degree of particle aggregation plays a more important role than the degree of graphitization, which is very low as showed by XRD results. It has been shown in the literature ${ }^{51,54}$ that carbon materials with small particle size and low degree of particle aggregation tend to decompose at lower temperatures $\left(250-450{ }^{\circ} \mathrm{C}\right)$ than highly aggregated materials. The lowest decomposition temperature displayed by $\mathrm{CMFe}$ could be associated with its low degree of particle aggregation compared to $\mathrm{CMNi}$ and $\mathrm{CMCo}$, as will be discussed later for TEM results. It has been shown ${ }^{51}$ that amorphous aggregates of particles
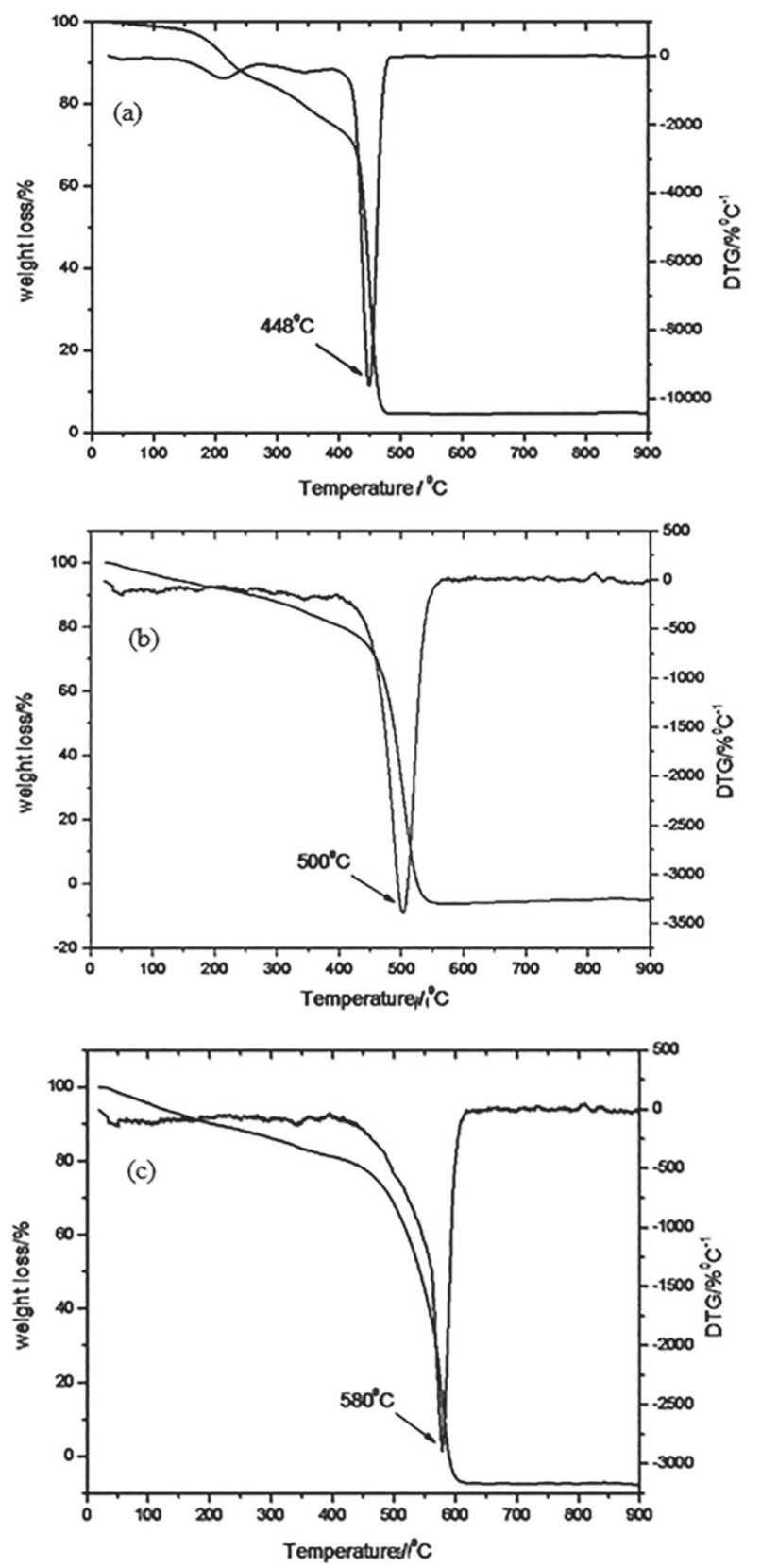

Figure 4. TG/DTG curves of (a) CMFe; (b) CMNi and (c) CMCo.

with diameters higher than around $10 \mathrm{~nm}$ in singlewalled carbon nanotube (SWNT) or multi-walled carbon nanotube (MWNT) materials can oxidize at temperatures as high as $600^{\circ} \mathrm{C}$, which may be the case of CMCo and CMNi.

It is important to conclude by the analysis of XRD, Raman and TG results that Fe produces a better organized carbon structure than $\mathrm{Ni}$ and $\mathrm{Co}$. As discussed in the literature,,$^{50}$ carbon nanotubes prepared from $\mathrm{Fe}$ catalyst also displayed a high degree of crystallinity and density as well as small diameter tubes compared to those prepared with Co. The ability of those metals to form well-organized carbon structures is related to its catalytic activity for the 
decomposition and diffusion of hydrocarbon precursors on the active site. ${ }^{49}$

SEM images obtained for the CM materials did not present many details of the particles morphology as can be observed in the image of CMFe (Figure 5a). However, TEM images (Figures 5b-5g) clearly showed aggregates of spherical particles formed by graphitic segments as observed for carbon black and soot particles. ${ }^{54}$ For all CM materials it was possible to observe in the low magnification TEM images (Figures 5c, $5 \mathrm{e}$ and $5 \mathrm{~g}$ ), dark areas resulting from the superposition of concentric carbon structures. It is important to emphasize that CMNi (Figure 5e) and CMCo (Figure $5 \mathrm{~g}$ ) present a higher degree of aggregation than that observed for CMFe (Figure 5c). Amorphous carbon could also be observed between the more graphitized structures in CMNi (Figure 5d, indicated by arrows), which according to the literature can be removed by oxidation in air. ${ }^{55}$ TEM images of CMCo (Figure 5f) showed hollow carbon structures (also indicated by arrows) as well as carbon nanoribbons.

The surface chemical composition of CM samples was determined by XPS measurements. Figures $6 a-6 c$ display $\mathrm{C} 1 \mathrm{~s}$ high resolution spectra which were fitted by Doniach-Sunjic function, ${ }^{56,57}$ considering the asymmetry of the $\mathrm{C}$-sp ${ }^{2}$ line shapes. O1s spectra (Figures 6d-6f) were fitted by a Gaussian-Lorentzian curve-fitting method..$^{58} \mathrm{As}$ shown in Table 1, the surface carbon atomic concentration values determined for $\mathrm{CMFe}, \mathrm{CMNi}$ and $\mathrm{CMCo}$ are 95.7, 97.1 and 95.9 at\%, respectively. Similar values of oxygen atomic concentrations were determined for the three samples, ranging from 2.9 to 4.1 at $\%$. A very low amount

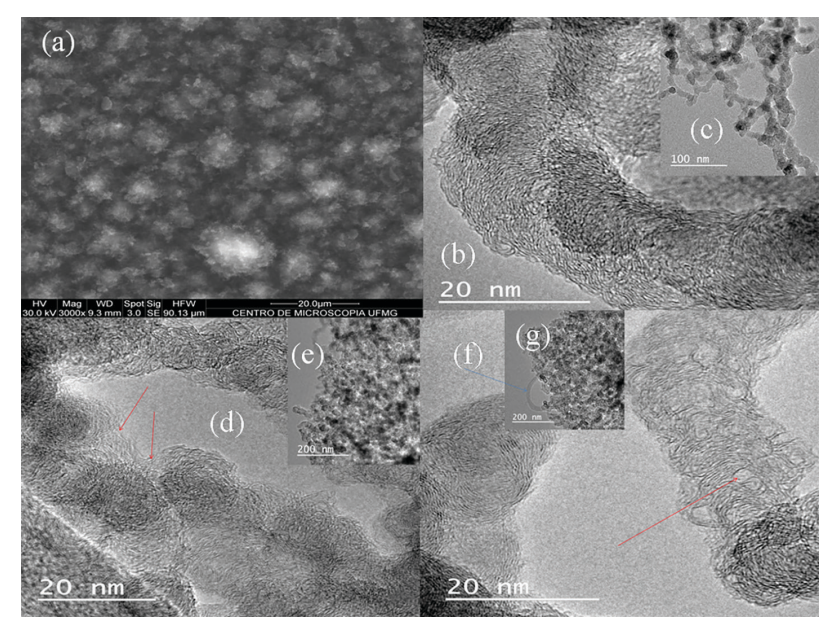

Figure 5. SEM image of (a) CMFe and TEM images of (b, c) CMFe; (d, e) CMNi and (f, g) CMCo.

of nitrogen (1.2 at\%) was detected for CMFe, probably $\mathrm{N}_{2}$ gas was adsorbed at the surface. Surface amount of Fe, $\mathrm{Co}, \mathrm{Ni}$ in the obtained $\mathrm{CM}$ materials is under the detection limit of XPS (around 0.1 at $\%$ ), ${ }^{59}$ which indicates that there are no encapsulated metal particles in the carbon structures as can also be observed in the TEM images presented above. These metal particles were probably removed from the hot zone of the tubular furnace by the gas used in the decomposition experiments. All samples present functionalized surfaces as could be observed after $\mathrm{C} 1 \mathrm{~s}$ peak fitting. CMNi presents the highest amount of superficial $\mathrm{C}$-sp ${ }^{2}, 54.6$ at $\%$. Oxygen containing chemical groups such as carbonyl $(\mathrm{C}=\mathrm{O})$, hydroxyl $(\mathrm{COOH})$ and $\mathrm{C}-\mathrm{OH}$ were detected in all studied samples, but it is important to point out that $\mathrm{CMNi}$ and $\mathrm{CMCo}$ samples presented the highest
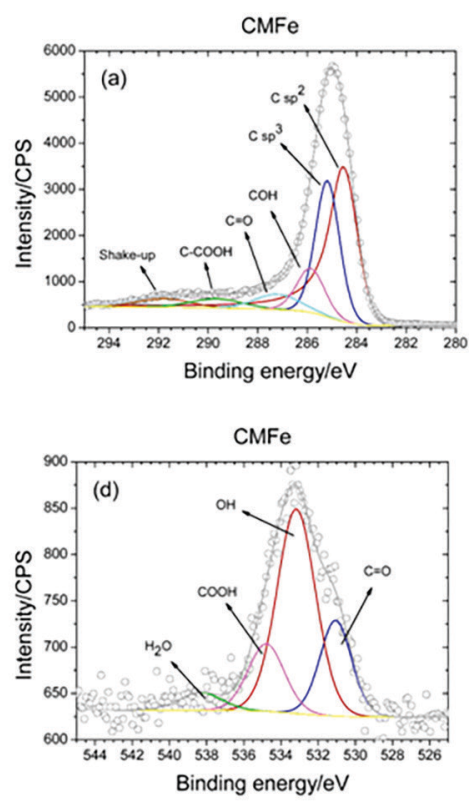
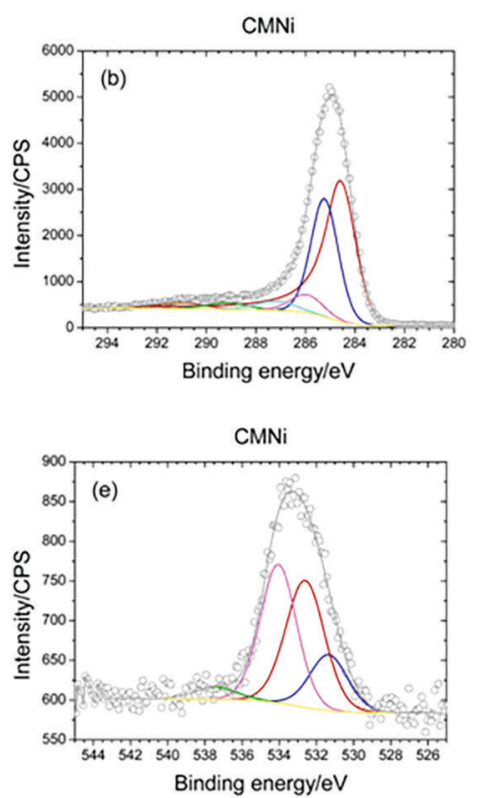
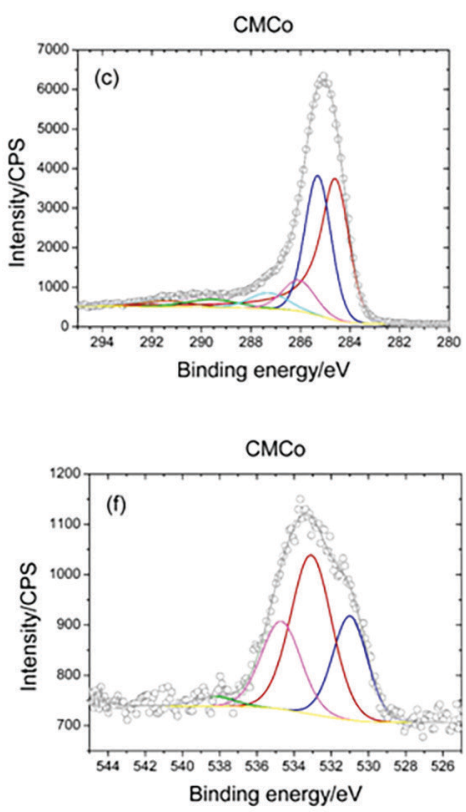

Figure 6. (a-c) C1s and (d-f) O1s XPS high resolution spectra obtained for CM samples. 
Table 1. Results of XPS analysis of the $\mathrm{C} 1 \mathrm{~s}$ and $\mathrm{O} 1 \mathrm{~s}$ content of the surfaces of different CM samples, where at\% is the surface atomic concentration

\begin{tabular}{|c|c|c|c|c|c|c|}
\hline Sample & 1s peak & Position / eV & $\begin{array}{c}\text { Surface atomic } \\
\text { concentration / at } \%\end{array}$ & $\begin{array}{l}\text { Carbon chemical } \\
\text { state }\end{array}$ & Position / eV & $\begin{array}{c}\text { Surface atomic } \\
\text { concentration / at } \%\end{array}$ \\
\hline \multirow[t]{3}{*}{$\mathrm{CMFe}$} & $\mathrm{C}$ & 284.5 & 95.7 & $\mathrm{C}-\mathrm{sp}^{2}$ & 284.6 & 48.1 \\
\hline & $\mathrm{O}$ & 532.5 & 3.1 & $\mathrm{C}-\mathrm{sp}^{3}$ & 285.2 & 27.8 \\
\hline & $\mathrm{N}$ & 399.5 & 1.2 & $\mathrm{C}-\mathrm{OH}$ & 286.6 & 4.6 \\
\hline \multirow[t]{5}{*}{ CMNi } & $\mathrm{C}$ & 284.4 & 97.1 & $\mathrm{C}-\mathrm{sp}^{2}$ & 284.6 & 54.6 \\
\hline & $\mathrm{O}$ & 532.4 & 2.9 & $\mathrm{C}-\mathrm{sp}^{3}$ & 285.2 & 31.1 \\
\hline & & & & $\mathrm{C}-\mathrm{OH}$ & 286.0 & 5.6 \\
\hline & & & & $\mathrm{C}=\mathrm{O}$ & 287.2 & 3.4 \\
\hline & & & & $\mathrm{COOH}$ & 289.2 & 2.6 \\
\hline \multirow[t]{5}{*}{$\mathrm{CMCo}$} & $\mathrm{C}$ & 284.6 & 95.9 & $\mathrm{C}-\mathrm{sp}^{2}$ & 284.6 & 46.8 \\
\hline & $\mathrm{O}$ & 532.6 & 4.1 & $\mathrm{C}-\mathrm{sp}^{3}$ & 285.3 & 32.3 \\
\hline & & & & $\mathrm{C}-\mathrm{OH}$ & 286.1 & 9.0 \\
\hline & & & & $\mathrm{C}=\mathrm{O}$ & 287.3 & 5.4 \\
\hline & & & & $\mathrm{COOH}$ & 289.6 & 3.7 \\
\hline
\end{tabular}

degree of surface functionalization, approximately 11.6 and 18 at $\%$, respectively, resulting from a sum of the at $\%$ of all oxygenated chemical functions. ${ }^{60}$

The use of carbon materials as electrodes in a supercapacitor is limited to the presence of pores, in this material, available for the electrolyte ions. ${ }^{61,62}$ For solvated electrolytes, the pore size at the electrode should be large enough to allow the ions to be accommodated.

In order to investigate the porosity of CM samples, nitrogen gas sorption experiments were carried out and the obtained isotherms are shown in Figure 7a. The isotherms were classified as type II, typical of materials with small adsorbate-adsorbent interaction potentials. The hysteresis loop was observed in all isotherms, and the shape is characteristic of materials with uniform mesopores. ${ }^{63,64}$ The hysteresis loops extended from $\mathrm{P} / \mathrm{P}_{0}=0.33$ to 0.96 and $\mathrm{P} / \mathrm{P}_{0}=0.30$ to 0.97 for $\mathrm{CMNi}$ and $\mathrm{CMFe}$, respectively. However, for $\mathrm{CMNi}$, the high volume of $\mathrm{N}_{2}$ adsorbed until $\mathrm{P} / \mathrm{P}_{0}=0.2$ indicates the presence of micropores (pores with size smaller than $20 \AA$ ).

The large slope observed on the hysteresis curve of CMFe for values of $\mathrm{P} / \mathrm{P}_{0}$ greater than 0.90 indicates the presence of large amount of mesopores and macropores.

The pore structure parameters obtained for the $\mathrm{CM}$ materials are summarized in Table 2 . The largest specific surface area, $\mathrm{S}_{\mathrm{BET}}$, was observed for $\mathrm{CMNi}, 277 \mathrm{~m}^{2} \mathrm{~g}^{-1}$. $\mathrm{S}_{\mathrm{BET}}$ values obtained for CMFe and CMCo, 52 and $71 \mathrm{~m}^{2} \mathrm{~g}^{-1}$, respectively, are very low compared to the one of CMNi. These $S_{\text {BET }}$ values are low compared to the ones described in the literature for hollow carbon nano-onions. ${ }^{65}$ The average pore size values of $\mathrm{CMNi}$ and $\mathrm{CMCo}, 80$ and $66 \AA$, respectively, were significantly lower than the value of $\mathrm{CMFe}, 336 \AA$. CMNi showed the highest average pore volume, $\mathrm{V}_{\mathrm{p}}, 0.55 \mathrm{~cm}^{3} \mathrm{~g}^{-1}$, however, with pore diameters smaller than determined for CMFe. Pore size distributions
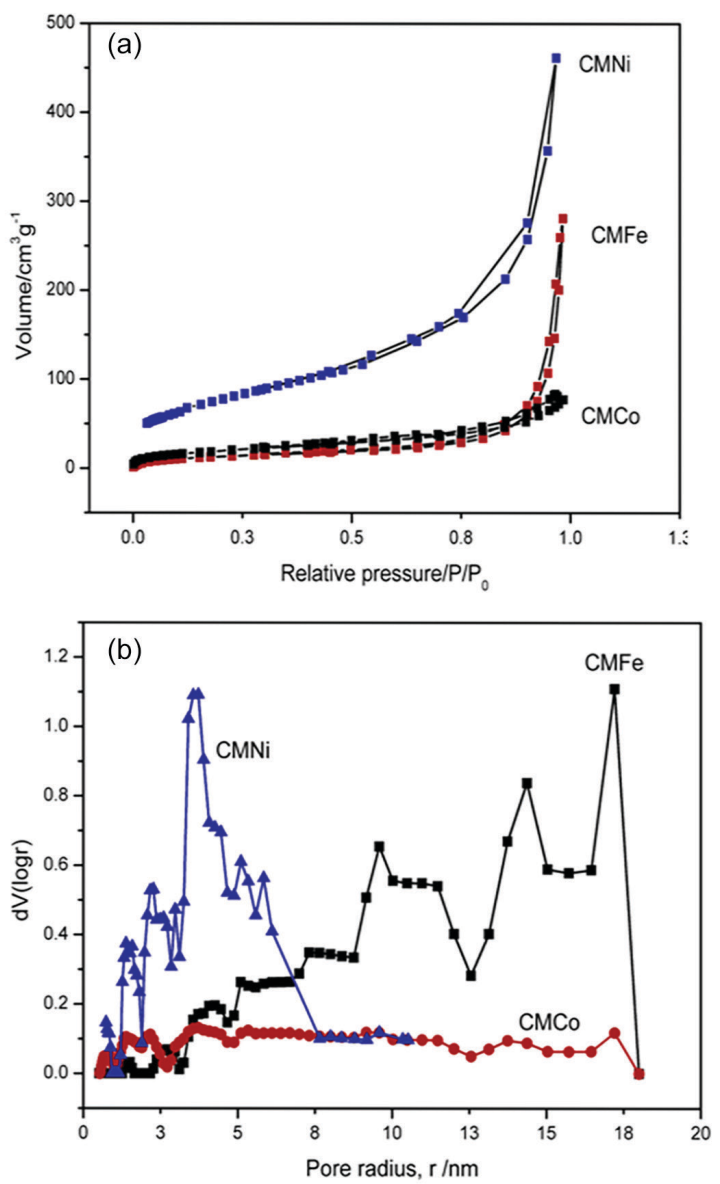

Figure 7. Nitrogen physisorption isotherms (a) and PSD curves (b) obtained for $\mathrm{CMFe}, \mathrm{CMNi}$ and CMCo. 
(PSD) curves (Figure 7b) were calculated using density functional theory (DFT) model for gas sorption data, which was used to define the PSD in porous activated carbon. ${ }^{66}$ As can be seen in the PSD curve of CMFe the majority of pore radii ranges from 10 to $18 \mathrm{~nm}$, indicating a high degree of mesoporosity. For CMNi a large volume of pores with $4 \mathrm{~nm}$ radius was observed, which is characteristic of materials containing micropores. PDS curve of CMCo indicated that this material presented the lowest volume of pores, $0.12 \mathrm{~cm}^{3} \mathrm{~g}^{-1}$ (Table 2). It is possible to conclude from $\mathrm{N}_{2}$ adsorption data that CMNi presented the largest surface area and its structure shows only micropores, while $\mathrm{CMFe}$ is a mesoporous material with a lower surface area than the former.

Table 2. Specific surface area, average pore volume, and average pore size, obtained by nitrogen adsorption measurements

\begin{tabular}{lccc}
\hline Sample & $\mathrm{S}_{\mathrm{BET}} /\left(\mathrm{m}^{2} \mathrm{~g}^{-1}\right)$ & $\mathrm{V}_{\mathrm{p}} /\left(\mathrm{cm}^{3} \mathrm{~g}^{-1}\right)$ & $\mathrm{D} / \AA$ \\
\hline $\mathrm{CMFe}$ & 52 & 0.43 & 336 \\
$\mathrm{CMNi}$ & 277 & 0.55 & 80 \\
$\mathrm{CMCo}$ & 71 & 0.12 & 66 \\
\hline
\end{tabular}

$\mathrm{S}_{\mathrm{BET}}$ : specific surface area; $\mathrm{V}_{\mathrm{p}}$ : average pore volume; $\mathrm{D}$ : average pore size.

As discussed in the literature, ${ }^{66}$ non-rigid porous materials are formed by assemblages of individual particles, and they may be referred to as aggregates. These particles can not only present internal (or intraparticle), but also interparticle voids. Internal pores will be smaller, in size and in total volume, than the interparticle voids. As could be observed in TEM images, porosity of these materials seems to be associated with interparticle voids rather than intraparticle, hollow carbon structures were observed only for CMCo (Figure 5f).

Cyclic voltammetry curves (CV) obtained for the CM samples in $\mathrm{KOH}$ aqueous solutions (Figure 8) present hysteresis behavior typical for capacitors charge/discharge processes. The reduction of the scan rates leads to a decrease of the CV area and the curves show an almost rectangular shape due to an increase of the double layer formation period. The reduction peaks corresponding to the oxygen reduction reaction (ORR) were observed for potentials below $-0.2 \mathrm{~V}$ and these cathodic peaks shift to higher potentials with decrease of scan rates. The ORR is reported to occur in alkaline medium in graphite electrodes through two different mechanisms, one less efficient, which involves the formation of peroxide intermediate, and another, more efficient, is a direct mechanism which involves 4 electrons ${ }^{65}$ (Figure 8). The specific capacitance is usually higher at low voltage scan rates for porous materials. The charge/discharge effects occur by $\mathrm{H}^{+}$and
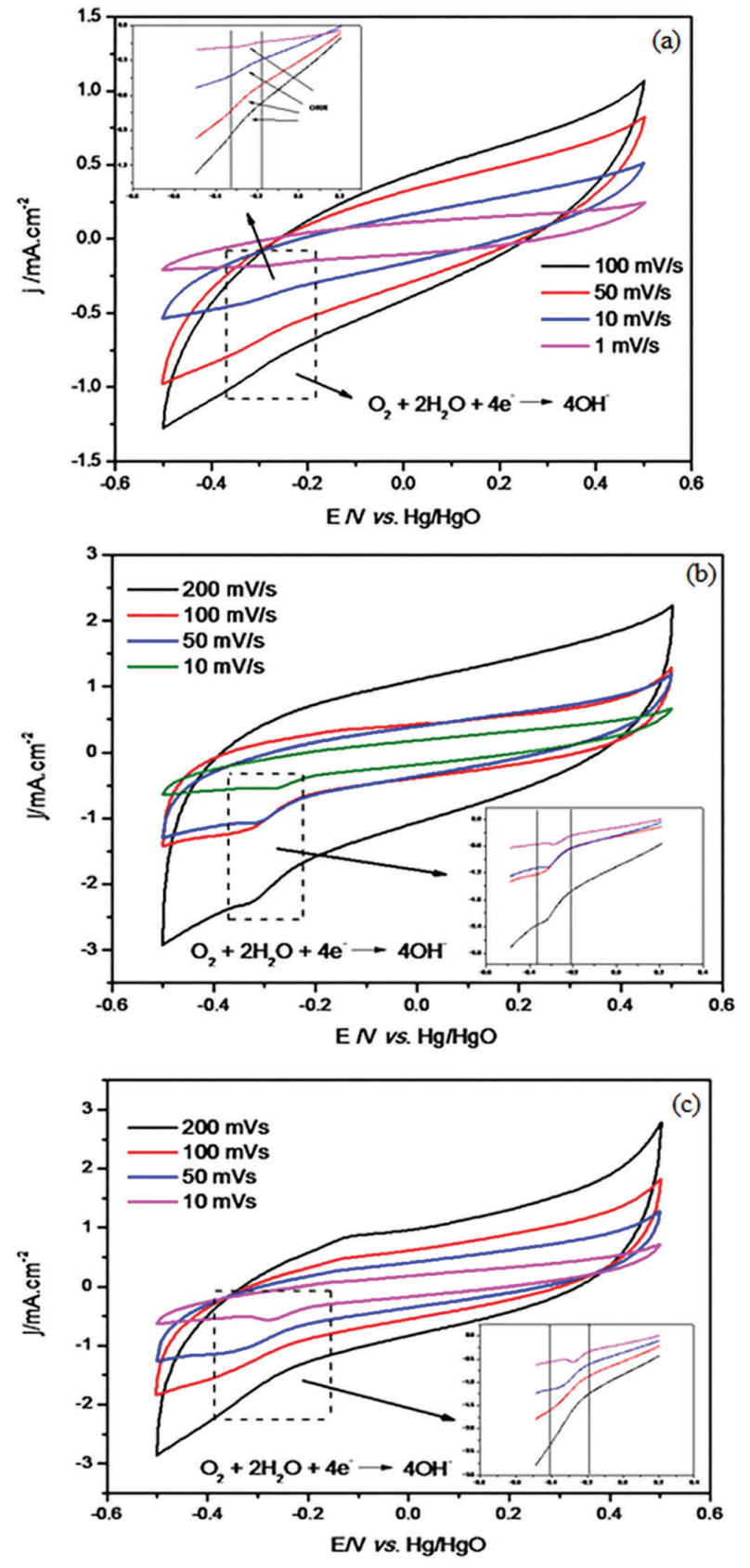

Figure 8. Cyclic voltammetry curves obtained at different scan rates in $\mathrm{KOH}$ aqueous solution (1 M) for (a) $\mathrm{CMFe}$; (b) $\mathrm{CMNi}$ and (c) $\mathrm{CMCo}$.

$\mathrm{OH}^{-}$diffusion process from the electrolyte solution to the electrode surface. High scan rates demand high ion diffusion and migration processes, thus these species do not have time to accumulate at surface of the electrode exhibiting a more resistive behavior. ${ }^{67}$

The voltammograms obtained in $\mathrm{H}_{2} \mathrm{SO}_{4}$ aqueous solutions (Figure 9) also showed hysteresis behavior. For CMNi (Figure 9b) and CMCo (Figure 9c), reduction peaks were observed in the cathodic curves. These peaks have been reported in many studies regarding the electrochemical performance of carbon materials ${ }^{65,68,69}$ and are associated 

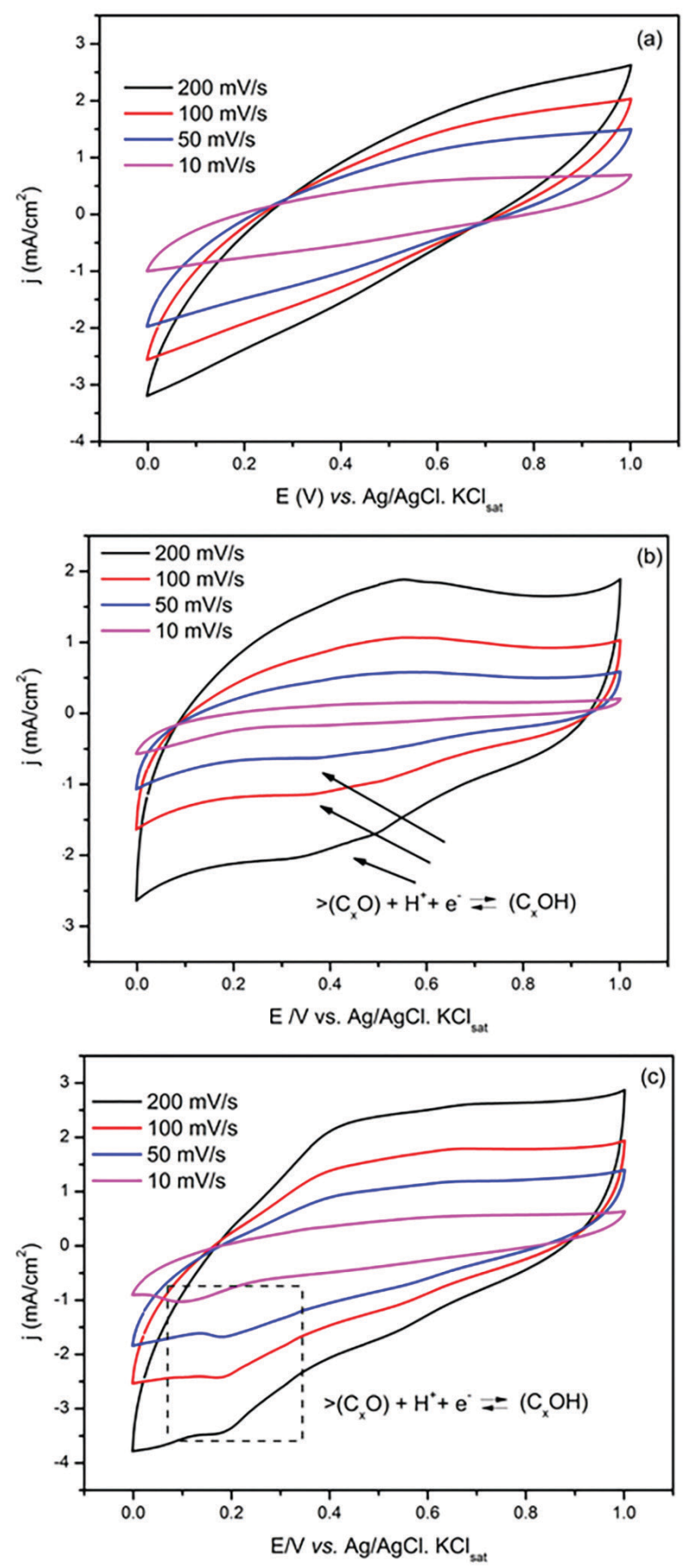

Figure 9. Cyclic voltammetry curves obtained at different scan rates in $\mathrm{H}_{2} \mathrm{SO}_{4}$ aqueous solution (1 M) for (a) $\mathrm{CMFe}$; (b) $\mathrm{CMNi}$ and (c) $\mathrm{CMCo}$.

with redox reactions of oxygen functional groups and with $\mathrm{H}^{+}$adsorption on these groups. Some authors ${ }^{70,71}$ have proposed the following reactions for these processes:

$>\left(\mathrm{C}_{\mathrm{x}} \mathrm{O}\right)+\mathrm{H}^{+} \rightarrow\left(\mathrm{C}_{\mathrm{x}} \mathrm{O}\right) / / \mathrm{H}^{+}$
$>\left(\mathrm{C}_{\mathrm{x}} \mathrm{O}\right)+\mathrm{H}^{+}+\mathrm{e}^{-} \rightarrow\left(\mathrm{C}_{\mathrm{x}} \mathrm{OH}\right)$

where $>$ is the surface of the carbon material and // is the adsorption interface between $\mathrm{H}^{+}$and the oxygen functional groups.

As both processes take place simultaneously during voltammetry measurements, the shape of voltammetry curves will depend on the electron transfer mechanisms for each material. As observed from XPS results, both CMNi and CMCo presented a higher concentration of oxygen functional groups in which the carbon atom presents high oxidation number $(\mathrm{C}=\mathrm{O}$ and $\mathrm{COOH})$, while $\mathrm{CMFe}$ exhibited mainly $\mathrm{C}-\mathrm{OH}$ functional groups. Thus, the redox reactions are more likely to be present in $\mathrm{CMNi}$ and $\mathrm{CMCo}$ samples while the $\mathrm{C}-\mathrm{OH}$ groups in $\mathrm{CMFe}$ might interact with $\mathrm{H}^{+}$ions without promoting electron transference.

The specific capacitance values $\left(\mathrm{C}_{\mathrm{S}}\right)$ for the obtained $\mathrm{CM}$ materials were calculated by the equation:

$\mathrm{C}_{\mathrm{S}}=\frac{\int \mathrm{idt}}{\Delta \mathrm{Em}}$

where $\mathrm{i}, \Delta \mathrm{E}$ and $\mathrm{m}$ are the capacitive current, the potential range and the $\mathrm{CM}$ mass deposited on the electrode surface, respectively. It is possible to observe in Figure 10 that as the potential scan rate decreases the specific capacitance increase due to the increase of the available surface area rising under limited ion diffusion. As can be seen in Table 3, the $\mathrm{C}_{\mathrm{S}}$ values obtained in acid medium are approximately 3 times greater than in alkaline electrolyte due to the smaller effective thickness of hydrate shells around $\mathrm{HSO}_{4}{ }^{-}$anions compared with the ones around $\mathrm{OH}^{-}$anions. ${ }^{72}$ The highest $\mathrm{C}_{\mathrm{S}}$ value was obtained for CMFe in acidic medium, $59 \mathrm{~F} \mathrm{~g}^{-1}$ (Table 3). However, for activated porous carbon, the $C_{S}$ values can exceed $300 \mathrm{~F} \mathrm{~g}^{-1}$ in aqueous electrolytes. ${ }^{73}$

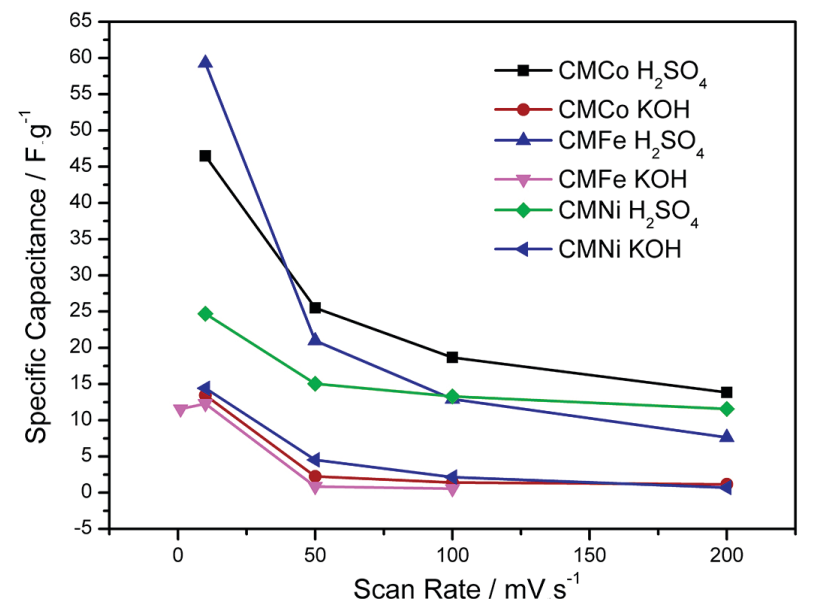

Figure 10. Specific capacitance as function of scan rate obtained in different electrolyte solutions.

As pointed out before, the distribution of pore sizes and/or constrictions at the entrance of the pores leads to 
Table 3. Specific capacitance obtained by cyclic voltammetry measurements with $10 \mathrm{mV} \mathrm{s}^{-1}$ scan rate

\begin{tabular}{lcc}
\hline Sample & $\mathrm{C}_{\mathrm{S}}$ in $\mathrm{KOH} /\left(\mathrm{F} \mathrm{g} \mathrm{g}^{-1}\right)$ & $\mathrm{C}_{\mathrm{S}}$ in $\mathrm{H}_{2} \mathrm{SO}_{4} /\left(\mathrm{F} \mathrm{g}^{-1}\right)$ \\
\hline $\mathrm{CMFe}$ & 12 & 59 \\
$\mathrm{CMNi}$ & 14 & 25 \\
$\mathrm{CMCo}$ & 14 & 46 \\
\hline
\end{tabular}

$\mathrm{C}_{\mathrm{S}}$ : specific capacitance.

significant changes in the $\mathrm{C}_{\mathrm{S}}$ values, as described in the work of Pohlmann et al. ${ }^{74}$ who investigated the effect of pore accessibility and surface area of activated carbons for ionic liquids used as electrolytes in supercapacitors. As discussed for the PSD curves obtained from nitrogen gas sorption experiments, $\mathrm{CMFe}$ presented the highest $\mathrm{C}_{\mathrm{S}}$ value observed in $\mathrm{H}_{2} \mathrm{SO}_{4}$, compared to $\mathrm{CMNi}$ and $\mathrm{CMCo}$. In this case, the electrolyte solvate, the $\mathrm{SO}_{4}{ }^{2-}$ ion, can easily access the $\mathrm{CMFe}$ mesopores. The lower $\mathrm{C}_{\mathrm{S}}$ value observed for $\mathrm{CMNi}$, compared to $\mathrm{CMFe}$, was due to the presence of only micropores in its structure, which are not accessible for electrolyte ions, despite its large surface area. Besides, CMFe presented the highest graphitization degree, as observed from XRD and Raman results, which led to its improved electronic conductivity, contributing to the higher specific capacitance displayed by this material. The $\mathrm{C}_{\mathrm{S}}$ value obtained for $\mathrm{CMCo}, 46 \mathrm{~F} \mathrm{~g}^{-1}$, was lower than the one of CMFe, $59 \mathrm{~F} \mathrm{~g}^{-1}$, but higher than the one of CMNi, $25 \mathrm{~F} \mathrm{~g} \mathrm{~g}^{-1}$ (Table 3). The values of $\mathrm{C}_{\mathrm{S}}$ obtained in basic medium, 12-14 $\mathrm{F} \mathrm{g}^{-1}$, are approximately the same for all the studied samples, indicating that the $\mathrm{OH}^{-}$electrolyte has equal access to micro and mesopores.

Several carbon-based materials have been reported in the literature for applications in supercapacitors. ${ }^{17,75,76}$ For carbon nanotubes and similar materials, the specific capacitance in aqueous electrolytes ranges from 50 to $100 \mathrm{~F} \mathrm{~g}^{-1}$, which is in good agreement with the results displayed by the materials in this work. Although many studies present the synthesis of carbon materials with much higher capacitance values, like induced verticalaligned carbon nanotubes and polyaniline nanocomposites $\left(403 \mathrm{~F} \mathrm{~g}^{-1}\right),{ }^{77}$ reduced graphene oxide films using a standard LightScribe DVD optical drive $\left(276 \mathrm{~F} \mathrm{~g} \mathrm{~g}^{-1}\right)^{78}$ and random single walled nanotubes networks $\left(180 \mathrm{~F} \mathrm{~g}^{-1}\right){ }^{79}$ the synthesis procedures of these carbon materials mostly show great difficulties to scale up the production for commercialization of supercapacitors. Therefore, the major advantage of preparing organized carbon materials using the method described in the present study is the higher scalability that it offers when compared to other preparation techniques from the literature.

\section{Conclusions}

Carbon materials were obtained in this work using low working temperatures, $700{ }^{\circ} \mathrm{C}$, and organometallic precursors which worked as catalysts and carbon source. The obtained materials did not present high degree of graphitization as was observed in XRD data. According to XRD, Raman and TG results, CMFe material showed the highest degree of structural organization compared to CMNi and CMCo. XPS data showed that both CMNi and CMCo presented a higher concentration of oxygen functional groups in which the carbon atom presents high oxidation number $(\mathrm{C}=\mathrm{O}$ and $\mathrm{COOH})$, while $\mathrm{CMFe}$ exhibited mainly $\mathrm{C}-\mathrm{OH}$. This explains the redox reactions involving oxygen containing carbon groups observed in the voltammograms of CMNi and CMCo. The absence of encapsulated metals in these materials, as confirmed by the XPS data, is an advantage compared to other methods using metal catalysts. Nitrogen adsorption measurements showed that the samples presented low values of specific surface area, in the range of 277 to $52 \mathrm{~m}^{2} \mathrm{~g}^{-1}$. The porous size distribution curves showed that the CMNi and CMCo materials present microporous and the $\mathrm{CMFe}$ is formed by mesopores. The highest specific capacitance value obtained for $\mathrm{CMFe}$ in acidic medium, $59 \mathrm{~F} \mathrm{~g}^{-1}$, was associated with the presence of mesoporous which are accessible for electrolyte ions, despite its low surface area.

\section{Acknowledgments}

H. V. da Silva would like to thank CAPES for the MSc scholarship. Authors acknowledge FAPEMIG (edital 19/2013 PRONEX CEX APQ 01626-14 and edital 01/2015, Demanda Universal CEX, APQ-01760-15 and PPM-00431-17) and CNPq for financial support. The HRTEM images were obtained at Centro de Microscopia (UFMG), Brazil.

\section{References}

1. Chrzanowska, J.; Hoffman, J.; Małolepszy, A.; Mazurkiewicz, M.; Kowalewski, T. A.; Szymanski, Z.; Stobinski, L.; Phys. Status Solidi B 2015, 252, 1860.

2. Das, R.; Shahnavaz, Z.; Ali, M. E.; Islam, M. M.; AbdHamid, S. B.; Nanoscale Res. Lett. 2016, 11, 1.

3. Maheshwar, S.; Madhuri, S.; Carbon Nano Forms and Applications; McGraw-Hill Companies Inc.: New Delhi, India, 2010.

4. Su, Y.; Zhang, Y.; Carbon 2015, 83, 90.

5. Merchan-Merchan, W.; Saveliev, A. V.; Kennedy, L.; Jimenez, W. C.; Prog. Energy Combust. Sci. 2010, 36, 696. 
6. Ugale, A. D.; Jagta, R. V.; Pawar, D.; Datar, S.; Kale, S. N.; Alegaoonkar, P. S.; RSC Adv. 2016, 6, 97266.

7. Yang, S.; Bachman, R. E.; Feng, X.; Acc. Chem. Res. 2012, 46, 116.

8. Rondeau-Gagne, S.; Morin, J.-F.; Chem. Soc. Rev. 2014, 43, 85.

9. Rao, C. N. R.; Govindaraj, A.; Acc. Chem. Res. 2012, 35, 998.

10. Morin, J.-F.; Synlett 2013, 24, 2032.

11. Li, Q.; Yan, H.; Zhang, J.; Liu, Z.; Carbon 2004, 42, 829.

12. Titirici, M. M.; White, R. J.; Brun, N.; Budarin, V. L.; Su, D. S.; del Monte, F.; Clark, J. H.; MacLachlan, M. J.; Chem. Soc. Rev. 2015, 44, 250.

13. Sopronyi, M.; Sima, F.; Vaulot, C.; Delmotte, L.; Bahouka, A.; Matei, G. C.; Sci. Rep. 2016, 6, 39617.

14. Iqbal, N.; Wang, X.; Ge, J.; Yu, J.; Kim, H.-Y.; Al-Deyab, S. S.; El-Newehy, M.; Ding, B.; RSC Adv. 2016, 6, 52171.

15. Zeiger, M.; Jäckel, N.; Weingart, D.; Presser, V.; Carbon 2015 , 94, 507.

16. Qie, L.; Chen, W.; Xu, H.; Xiong, X.; Jiang, Y.; Zou, F.; Hu, X.; Xin, Y.; Zhang, Z.; Huang, Y.; Energy Environ. Sci. 2013, 6, 2497.

17. Zhang, L. L.; Zhao, X. S.; Chem. Soc. Rev. 2009, 38, 2520.

18. Vangari, M.; Tonya, P.; Li, J.; J. Energy Eng. 2012, 139, 72.

19. Kim, B. K.; Chabot, V.; Yu, A.; Electrochim. Acta 2013, 109, 370.

20. Fanguei, M.; Di, M.; Guang, W.; Weidan, G.; Jinqiu, S.; Shijiao, S.; Jianfeng, W.; Jieshan, Q.; Chem. Commun. 2016, 52, 6673.

21. Paris, O.; Zollfrank, C.; Zickler, G. A.; Carbon 2005, 43, 53.

22. Zickler, G. A.; Smarsly, B.; Gierlinger, N.; Peterlik, H.; Paris, O.; Carbon 2006, 44, 3239.

23. Gotabaczak, M.; Konstantynowicz, A.; J. Achiev. Mater. Manuf. Eng. (JAMME) 2009, 37, 270.

24. Ferrari, A. C.; Robertson, J.; Phys. Rev. B 2000, 61, 14095.

25. www.casaxps.com, accessed in March 2018.

26. Madhusudanan, P. M.; Mohammed, K. K.; Nair, C. G. R.; J. Therm. Anal. Calorim. 1975, 8, 31.

27. Singhal, S.; Garg, A. N.; Chandra, K.; J. Therm. Anal. Calorim. 2004, 78, 941

28. Manoj, B.; Kunjomana, A. G.; Int. J. Electrochem. Sci. 2012 , 7, 3127.

29. Barnakov, Ch. N.; Khokhlova, G. P.; Popova, A. N.; Sozinov, S. A.; Ismagilov, Z. R.; Eurasian Chem.-Technol. J. 2015, 17, 87.

30. Lu, L.; Sharajwalla, V.; Kong, C.; Harris, D.; Carbon 2001, 39 , 18.

31. Siklitskaya, A. V.; Yastrebov, S. G.; Smith, R.; Nanosyst.: Phys., Chem., Math. 2016, 7, 340.

32. Feret, F. R.; Analyst 1998, 123, 595.

33. Kaniyoor, A.; Ramaprabhu, S.; AIP Adv. 2012, 2, 032183.

34. Dresselhaus, M. S.; Jorio, A.; Souza Filho, A. G.; Saito, R.; Philos. Trans. R. Soc., A 2010, 368, 5355.
35. Ferrari, A. C.; Meyer, J. C.; Scardaci, V.; Casiraghi, C.; Lazzeri, M.; Mauri, F.; Piscanec, S.; Novoselov, K. S.; Roth, S.; Geim, A. K.; Phys. Rev. Lett. 2006, 97, 187401.

36. Pimenta, M. A.; Dresselhaus, G.; Dresselhaus, M. S.; Cançado, L. G.; Jorio, A.; Saito, R.; Phys. Chem. Chem. Phys. 2007, 9, 1276.

37. Ferrari, A. C.; Solid State Commun. 2007, 143, 47.

38. Cuesta, A.; Dhamelincourt, P.; Laureyns, J.; Martinezalonso, A.; Tasconi, J. M. D.; Carbon 1994, 32, 1523.

39. Tuinstra, F.; Koenig, J. L.; J. Chem. Phys. 1970, 53, 1126.

40. Sadezky, A.; Muckenhuber, H.; Grothe, H.; Niessner, R.; Poschl, U.; Carbon 2005, 43, 1731.

41. Claramunt, S.; Varea, A.; López-Días, D.; Velázquez, M. M.; Cornet, A.; Cirera, A.; J. Phys. Chem. C 2015, 119, 10123.

42. Goodman, P. A.; Li, H.; Gao, Y.; Lu, Y. F.; Stenger-Smith, J. D.; Redepenning, J.; Carbon 2013, 55, 291.

43. Jawhari, T.; Roid, A.; Casado, J.; Carbon 1995, 33, 156.

44. Nakamizo, M.; Tamani, K.; Carbon 1984, 22, 197.

45. Simon, A.; Seyring, M.; Kamnitz, S.; Richter, H.; Voigt, I.; Rettenmayr, M.; Ritter, U.; Carbon 2015, 90, 25.

46. Wang, Q.; Allred, D. D.; Knight, L. V.; J. Raman Spectrosc. 1995, 26, 1039.

47. Knight, D. S.; White, W.; J. Mater. Res. 1989, 4, 385.

48. Cançado, L. G.; Takai, K.; Enoki, T.; Endo, M.; Kim, Y. A.; Mizusaki, H.; Jorio, A.; Coelho, L. N.; Magalhães-Paniago, R.; Pimenta, M. A.; Appl. Phys. Lett. 2006, 88, 163106.

49. Yudasaka, M.; Kikuchi, R. In Supercarbon, vol. 33; Yoshimura, S.; Chang, R. P. H., eds.; Springer Series in Materials Science: Berlin, Heidelberg, 1998, p. 99.

50. Romero, A.; Garrido, A.; Nieto-Márquez, A.; Sánchez, P.; de Lucas, A.; Valverde, J. L.; Microporous Mesoporous Mater. 2008, 110, 318 .

51. Trigueiro, J. P. C.; Silva, G. G.; Lavall, R. L.; Furtado, C. A.; Oliveira, S.; Ferlauto, A. S.; Lacerda, R. G.; Ladeira, L. O.; Liu, J.-W.; Frost, R. L.; George, G. A.; J. Nanosci. Nanotechnol. 2007, 7, 1 .

52. Chu, X.; Schmidt, L. D.; Surf. Sci. 1992, 268, 325.

53. Plonska-Brzezinska, M. E.; Lewandowski, M.; Błaszyk, M.; Molina-Ontoria, A.; Luciński, T.; Echegoyen, L.; Chem. Phys. Chem. 2012, 13, 4134.

54. Müller, J. O.; Su, D. S.; Jentoft, R. E.; Kröhnert, J.; Jentoft, F. C.; Schlögl, R.; Catal. Today 2005, 102-103, 259.

55. Zeiger, M.; Jäckel, N.; Aslan, M.; Weingarth, D.; Presser, V.; Carbon 2015, 84, 584.

56. Evans, S.; Surf. Interface Anal. 1991, 17, 85.

57. Doniach, S.; Sunjic, M.; J. Phys. C 1970, 3, 285.

58. Linford, M. R.; Vac. Technol. Coat. 2014, 2.

59. Shard, A. G.; Surf. Interface Anal. 2014, 46, 175.

60. Kundu, S.; Wang, Y.; Xia, W.; Muhler, M.; J. Phys. Chem. C 2008, 112, 16869.

61. Chen, T.; Dai, L.; Mater. Today 2013, 16, 272. 
62. Frackowiak, E.; Phys. Chem. Chem. Phys. 2007, 9, 1774.

63. Klose, M.; Pinkert, K.; Zier, M.; Uhlemann, M.; Wolke, F.; Taumann, J.; Giebeler, L.; Carbon 2014, 79, 302.

64. Rouquerol, J.; Rouquerol, F.; Llewellyn, P.; Maurin, G.; Sing, K. S.; Adsorption by Powders and Porous Solids: Principles, Methodology and Applications, $2^{\text {nd }}$ ed.; Elsevier-Academic Press: Amsterdam, 2014.

65. Frackowiak, E.; Beguin, F.; Carbon 2001, 39, 937.

66. Seaton, N. A.; Walton, J. P. R. B.; Quirke, N.; Carbon 1989, 27, 853; Zdravkov, B. D.; Cermak, J. J.; Sefara, M.; Janku, J.; Cent. Eur. J. Chem. 2007, 5, 385.

67. McDonough, J. K.; Gogotsi, Y.; Electrochem. Soc. Interface 2013, 22, 61 .

68. Li, W. Z.; Wang, D. Z.; Yang, S. X.; Wen, J. G.; Ren, Z. F.; Chen, J. H.; Carbon 2002, 40, 1193.

69. Barisci, J. N.; Wallace, G. G.; Baughman, R. H.; J. Electroanal. Chem. 2000, 488, 92.

70. Kinoshita, K.; Carbon: Electrochemical and Physicochemical Properties; Wiley: New York, 1988.

71. Hsieh, C. T.; Teng, H.; Carbon 2002, 40, 667.
72. Largeot, C.; Portet, C.; Chmiola, J.; Taberna, P. P.; Gogotsi, Y.; Simon, P.; J. Am. Chem. Soc. 2008, 130, 2730.

73. Cheng, P.; Gao, S.; Zang, P.; Yang, X.; Bai, Y.; Xu, H.; Liu, Z.; Lei, Z.; Carbon 2015, 93, 315.

74. Pohlmann, S.; Lobato, B.; Centeno, T. A.; Balducci, A.; Phys. Chem. Chem. Phys. 2013, 15, 17287.

75. Chen, T.; Dai, L.; Mater. Today 2013, 16, 272.

76. Caliman, C. C.; Mesquita, A. F.; Cipriano, D. F.; Freitas, J. C. C.; Cotta, A. A. C.; Macedo, W. A. A.; Porto, A. O.; RSC Adv. 2018, 8, 6136.

77. Wu, G.; Tan, P.; Wang, D.; Li, Z.; Peng, L.; Hu, Y.; Wang, C.; Zhu, W.; Chen, S.; Chen, W.; Sci. Rep. 2017, 7, 1.

78. El-Kady, M. F.; Strong, V.; Dubin, S.; Kaner, R. B.; Science 2012, 335, 1326.

79. An, K. H.; Kim, W. S.; Park, Y. S.; Moon, J.-M.; Bae, D. J.; Lim, S. C.; Lee, Y. S.; Lee, Y. H.; Adv. Funct. Mater. 2001, 11, 387.

Submitted: December 27, 2017

Published online: March 28, 2018 